\title{
Quantitative Real-Time PCR Detection of Airborne Staphylococcus aureus in Hospital Indoor Atmosphere
}

\author{
Zhitang $\mathrm{Lu}$ (Corresponding author) \\ College of Life Sciences, Hebei University \\ Key Laboratory of Microbial Diversity Research and Application of Hebei Province \\ Baoding 071002, China \\ E-mail:1zt325@sina.com \\ Jing Wang \& Yating Zhang \\ College of Life Sciences, Hebei University \\ Key Laboratory of Microbial Diversity Research and Application of Hebei Province \\ Baoding 071002, China
}

Received: December 21, 2011

Accepted: January 16, $2012 \quad$ Published: March 1, 2012

doi:10.5539/mas.v6n3p22

URL: http://dx.doi.org/10.5539/mas.v6n3p22

\begin{abstract}
Staphylococcus aureus is a classical type of gram-positive bacteria. It is attached to skin, mucous membranes, especially pharynx nasalis, as an opportunistic pathogen which can cause a wide variety of infectious diseases. With increasing use of antibiotic the resistance of Staphylococcus aureus is increased. And more and more methicillin-resistant Staphylococcus aureus which caused seriously disease emerged recent years. So a sensitive, rapid, and specific method was developed using real-time PCR to detect the number of Staphylococcus aureus survived in atmosphere of a specific respiration ward. In this study thirteen samples were collected and assessed in all during the second quarter of 2011.
\end{abstract}

Keywords: Staphylococcus aureus, Real-time PCR, Hospital atmosphere

\section{Introduction}

Hospital-acquired infection (HAI) is an important public health issue with unacceptable levels of morbidity and mortality, over the last 5 years. Disease can be transmitted by air (over large distances), by direct/indirect contact or a combination of both routes (Eames, et al., 2009). Staphylococcus aureus as an opportunistic pathogen that cause a wide variety of infectious diseases is a significant cause of hospital-acquired or nosocomial infections. And it is usually associated with humans as commensal colonizing organisms in at least $30 \%$ of the population (Kluytmans, et al., 1997; Cole, et al., 2001; Von, et al., 2001). It is commonly cause opportunistic infections primarily involving the skin and soft tissues; however, they are capable of causing much more serious systemic infections and death, especially when associated with methicillin resistance (Diep, et al., 2006; Klevens, et al., 2007). These infections have been linked to close contact and sharing of common facilities such as locker rooms, schools and prisons (Plano, et al., 2011).

With the increasing use of the antibiotic, especially methicillin, more and more methicillin-resistant Staphylococcus aureus (MRSA) emerged. MRSA was first isolated in the United States in 1968. By 2003, nearly $60 \%$ of $S$. aureus isolates recovered from patients in intensive care units (ICUs) were MRSA (Siegel, et al., 2006). Notably, it appears that MRSA does not replace the methicillin-susceptible strains of S. aureus (MSSA) as a cause of disease but rather adds to the total burden of S. aureus infection in the population (Anderson, et al., 2007; Kaplan, et al., 2005). Thus, rapid and accurate determination of $S$. aureus including MRSA colonization can be a critical factor for the success of HAI control program.

The real-time PCR method combines PCR chemistry with fluorescence detection of amplified product in the same reaction vessel. Real-time PCR testing platforms provide equivalent sensitivity and specificity as conventional PCR combined with Southern blot analysis. The combination of excellent sensitivity and specificity, low contamination risk, ease of performance and speed, has made real-time PCR technology an 
appealing alternative to conventional culture-based or immunoassay-based testing methods used in the clinical microbiology for diagnosing many infectious diseases (Espy, et al., 2006).

\section{Materials and Methods}

\subsection{Sampling and Pretreatment}

The air samples were collected from a certain respiration ward of a hospital located in the urban district of Baoding, China. Averagely, there are 3-4 patients and some accompanies in the room. Air sample was collected by vacuum pump $(50 \mathrm{~L} / \mathrm{min})$ linked to a syringe filter with $50 \mathrm{~mm}$ in diameter supplied with cellulose membrane of $0.22 \mu \mathrm{m}$ pore size during the second quarter of 2011. During this period of time we collected sample on Sunday every week at 8:00 am in a specific ward which was disinfected at 6:00 pm everyday in the hospital. After collected for $2 \mathrm{hrs}$ the filtered objects were washed with $10 \mathrm{~mL}$ of TE buffer $(100 \mathrm{mmol} / \mathrm{L}$ Tris-Cl, 10 $\mathrm{mmol} / \mathrm{L}$ EDTA, $\mathrm{pH}$ 8.0) from membrane, centrifuged for 5 minutes(10000 rpm), re-suspended in a $1.5 \mathrm{~mL}$ tube with TE buffer and ready for DNA extraction.

\subsection{DNA Extraction}

The Soil genomic DNA fast isolation kit (BioTeke Corporation) was used to extract the metagenomic DNA of the air samples and the sample for standard real-time PCR curve. The sample for standard real-time PCR curve was prepared by supplementing biomass of Staphylococcus aureus CGMCC 1.89 quantitatively into an autoclaved air sample. In the process of operation the most steps of the procedure were carried out according to the manufacturer's instructions, but the lysis step was modified. Because the Staphylococcus DNA was rather difficult to extract in ordinary procedure and many members of the Staphylococcus are pathogenic, 12U lysostaphin (Sangon Biotech) was added in the lysis step when the sample was incubated at $37{ }^{\circ} \mathrm{C}$, and the incubation time was extended from $10 \mathrm{~min}$ to $30-60 \mathrm{~min}$ in order to improve the DNA productivity of airborne Staphylococcus.

\subsection{Specificity and Coverage of Primers}

The specificity and coverage of a pair of reported specific primers for the thermostable nuclease (nuc) gene of $S$. aureus, nucF: 5'-GCGATTGATGGTGATACGGTT -3' and nucR: 5'- AGCCAAGCCTTGACGAACTAA -3' (Hein, et al., 2001), were checked to discus the feasibility for the real-time quantitative PCR.

\subsection{The Establishment of Standard Curve for Real-time PCR}

\subsubsection{Preparation of Standard Samples}

The standard samples were prepared by the serial ten-fold dilution of the genomic DNA with known concentration (corresponding to $1.3 \times 10^{7} \mathrm{cfu} / \mu \mathrm{l} S$. aureus) obtained previously from the autoclaved air sample supplemented with $S$. aureus biomass using TE buffer into final concentrations corresponding to from $1.3 \times 10^{1}$ to $1.3 \times 10^{6} \mathrm{cfu} / \mu \mathrm{l}$.

\subsubsection{The Establishment of Standard Curve}

The real-time PCR reaction systems for standard curve consisted of $1 \mu \mathrm{l}$ of each standard samples, $10 \mu \mathrm{l}$ of $2 \times$ Ultra SYBR Mixture (with ROX) (CWBIO), $0.1 \mu \mathrm{l}$ of nucF' primer $(20 \mu \mathrm{moh}), 0.1 \mu \mathrm{l}$ of nucR' primer (20 $\mu \mathrm{moh})$ and $8.8 \mu \mathrm{l}$ RNase-free water. Additionally, a negative control reaction was also carried out. The reaction was performed on Bio-Rad Mini Opticon real-time PCR instrument. The protocol of real-time PCR was 10 min at $94{ }^{\circ} \mathrm{C}$, followed by 39 cycles of $10 \mathrm{~s}$ at $94{ }^{\circ} \mathrm{C}, 30 \mathrm{~s}$ at $59.2{ }^{\circ} \mathrm{C}$ and $90 \mathrm{~s}$ at $72{ }^{\circ} \mathrm{C}$. In the process of the amplification the parameters of the standard curve was installed. The parameters contain sample type, dye type, replication series, dilution series, especially dilution factor. At the end of the amplification an additional few minutes were required for the melting curve analysis. Then thermal cycling, fluorescent data collection, and data analysis were carried out (Leblanc-Maridor, et al., 2011).

\subsubsection{Quantify the S. aureus in Air samples Using Standard Curve}

The quantitative analysis of $S$. aureus of the ward air samples were carried out in the same system and procedure as described in 2.4.2 using the metagenomic DNA of the samples. And the quantities of the S. aureus of the samples were calculated by the threshold cycle $(\mathrm{Ct})$ values according to the standard curve established.

\section{Results and Discussion}

\subsection{Conditions in Sampling}

The site of sample is on the third floor of the building. The ward faces south and the atmosphere in it is flow. The sampling dates and weather conditions were list in Table 1. 


\subsection{The Specificity and Coverage of the Primers}

When the primers nucF: 5'-GCGATTGATGGTGATACGGTT -3' and nucR: 5'- AGCCAAGCCTTGA CGAACTAA -3' (Hein, et al., 2001) were used as queries in blast searches against the GenBank nucleotide collection, a number of $S$. aureus including some MRSA strains were not matched. The mismatch occurred in the forward primer. And the imprecise amplification condition will lead to nonspecific amplification. So we optimized the forward primer sequence as nucF': 5'-GCGATTGATGGTGATACKGT-3' and the reverse primer sequence keep unchanged as nucR': 5'-AGCCAAGCCTTGACGAACTAA-3'. When the sequences were searched against nucleotide collection of GenBank using BLAST, the both primers could match the target nuc gene of $S$. aureus strains exactly, no $S$. aureus strain was lost, and no other strain was matched. And a 269 bp product was expected.

\subsection{Quantification Using the Standard Curve}

In this study the Bio-Rad Mini Opticon real-time PCR instrument which has 48 wells was used to establish the standard curve and to check the $S$. aureus content of the thirteen air samples. The standard curve established in this study was automatically generated by the instrument and shown in Figure 1. Through this standard curve the efficiency (E) of PCR amplification was estimated using the slope of the standard curve and the formula $\mathrm{E}=$ $10^{(-1 / \text { slope })}-1$. A reaction with $100 \%$ efficiency will generate a slope of -3.32 . In this study $\mathrm{E}$ is $93.1 \%$ and the sloop is -3.500 . We observed a strong linear correlation $\left(\mathrm{R}^{2}\right.$ values were all equal to 0.966$)$, providing an accurate measurement over a large variety of starting target amounts. The mean standard curve was: $\mathrm{y}=-3.500 \mathrm{x}$ $+39.920, \mathrm{R}^{2}=0.966$.

The $S$. aureus variation in thirteen samples was calculated and estimated as round numbers using the $\mathrm{Ct}$ values obtained by real-time PCR amplification (Figure 2).

April and May are in late spring and early summer in Baoding, the weather changed greatly. From the result of the number of $S$. aureus quantified, it is obviously that the number of the $S$. aureus is increased with the temperature increasing. But when it rains the number of $S$. aureus will decrease in a certain degree. It may due to some microbes in air were settled down by rainfall. It also showed a positive correlation with the number of patients and accompanies in the room. But generally speaking, the indoor atmosphere of the sampled respiration ward is not clean enough for the patients, and need to strengthen the daily air sterilization.

The new real-time PCR assay we evaluated in this paper had hands-on technologist processing time comparable to that of directly plated culture and thus can provide very rapid results with no increase in laboratory personnel. And real-time PCR is more automated and has a shorter test turnaround time, optimization experiments can be performed within hours instead of days.

\section{Conclusions}

The real-time PCR assays developed in this study provide an effective, rapid, and sensitive alternative method for the detection and the quantification of the $S$. aureus survived in the atmosphere especially in the hospital atmosphere. After detected using the thirteen samples collected during the second quarter of 2011 we found that the quantity of the $S$. aureus is varied along the season change and the people in the ward.

\section{References}

Anderson, D. J., Sexton, D. J., Kanafani, Z. A., Auten, G., \& Kaye, K. S. (2007). Severe surgical site infection in community hospitals: epidemiology, key procedures, and the changing prevalence of methicillin-resistant Staphylococcus aureus. Infect. Control Hosp. Epidemiol, 28, 1047-1053. http://dx.doi.org/10.1086/520731

Cole, A. M., Tahk, S., Oren, A., Yoshioka, D., Kim, Y. H., Park, A., \& Ganz, T. (2001). Determinants of Staphylococcus aureus nasal carriage. Clinical and Diagnostic Laboratory Immunology, 8, 1064-1069. http://dx.doi.org/10.1128/CDLI.8.6.1064-1069.2001

Diep, B. A., Carleton, H. A., Chang, R. F., Sensabaugh, G. F., \& Perdreau-Remington, F. (2006). Roles of 34 virulence genes in the evolution of hospital and community-associated strains of methicillin-resistant Staphylococcus aureus. The Journal of Infectious Diseases, 193, 1495-1503. http://dx.doi.org/10.1086/503777

Eames, I., Tang, J. W., Li, Y., \& Wilson, P. (2009). Airborne transmission of disease in hospitals. Journal of the Royal Society Interface, 6, 697-702. http://dx.doi.org/10.1098/rsif.2009.0407.focus

Espy, M. J., Uhl, J. R., Sloan, L. M., Buckwalter, S. P., Jones, M. F., Vetter, E. A., Yao, J. D. C., et al. (2006). Real-Time PCR in Clinical Microbiology: Applications for Routine Laboratory Testing. Clinical Microbiology Reviews, 19(1), 165-256. http://dx.doi.org/10.1128/CMR.19.1.165-256.2006 
Hein, I., Lehner, A., Rieck, P., Klein, K., Brandl, E., \& Wagner, M. (2001). Comparison of different approaches to quantify Staphylococcus aureus cells by real-time quantitative PCR and application of this technique for $\begin{array}{lllll}\text { examination of cheese. Appl Environ } & \text { Microbiol, } & 67(7), & \text { 3122-3126. }\end{array}$ http://dx.doi.org/10.1128/AEM.67.7.3122-3126.2001

Kluytmans, J., Van, B. A., \& Verbrugh, H. (1997). Nasal carriage of Staphylococcus aureus: epidemiology, underlying mechanisms, and associated risks. Clinical Microbiology Reviews, 10, 505-520.

Kaplan, S. L., Hulten, K. G., Gonzalez, B. E., Hammerman, W. A., Lamberth, L., Versalovic, J., \& Mason, E. O. (2005). Three-year surveillance of community-acquired Staphylococcus aureus infections in children. Clin Infect Dis., 40, 1785-1791. http://dx.doi.org/10.1086/430312

Klevens, R. M., Morrison, M. A., Nadle, J., Petit, S., Gershman, K., Ray, S., Harrison, L. H., et al. (2007). Invasive methicillin-resistant Staphylococcus aureus infections in the United States. The Journal of the American Medical Association, 298, 1763-1771. http://dx.doi.org/10.1001/jama.298.15.1763

Leblanc-Maridor, M., Beaudeau, F., Seegers, H., Denis, M., \& Belloc, C. (2011). Rapid identification and quantification of Campylobacter coli and Campylobacter jejuni by real-time PCR in pure cultures and in complex samples. Bio Med Central Microbiology, 11, 113. http://dx.doi.org/10.1186/1471-2180-11-113

Plano, L. R. W., Garza, A. C., Shibata, T., Elmir, S. M., Kish, J., Sinigalliano, C. D., Gidley, M. L., et al. (2011). Shedding of Staphylococcus aureus and methicillin-resistant Staphylococcus aureus from adult and pediatric bathers in marine waters. Bio Med Central Microbiol, 11(1), 5. http://dx.doi.org/10.1186/1471-2180-11-5

Siegel, J. D., Rhinehart, E., Jackson, M., Chiarello, L., \& the Healthcare Infection Control Practices Advisory Committee. (2006). Management of multidrug-resistant organisms in healthcare settings. American Journal of Infection Control, 35(10), 165-193. http://dx.doi.org/10.1016/j.ajic.2007.10.006

Von Eiff, C., Becker, K., Machka, K., Stammer, H., \& Peters, G. (2001). Nasal carriage as a source of Staphylococcus aureus bacteremia. The New England Journal of Medicine, 344, 11-16. http://dx.doi.org/10.1056/NEJM200101043440102

Table 1. Dates and conditions of sampling

\begin{tabular}{ccc}
\hline Serial Number & Date of Sampling & Weather condition \\
\hline 1 & 3th April 2011 & Sunny \\
2 & 10th April 2011 & Sunny, breeze \\
3 & 17th April 2011 & Sunny, Strong wind \\
4 & 24th April 2011 & Cloudy, breeze \\
5 & 1th May 2011 & Sunny, breeze \\
6 & 8th May 2011 & Rain, breeze \\
7 & 15th May 2011 & Sunny, breeze \\
8 & 22th May 2011 & Sunny, breeze \\
9 & 29th May 2011 & Thunder shower, breeze \\
10 & 5th June 2011 & Light rain, breeze \\
11 & 12th June 2011 & Sunny, breeze \\
12 & 19th June 2011 & Cloudy, breeze \\
13 & 26th June 2011 & Sunny, breeze \\
\hline
\end{tabular}




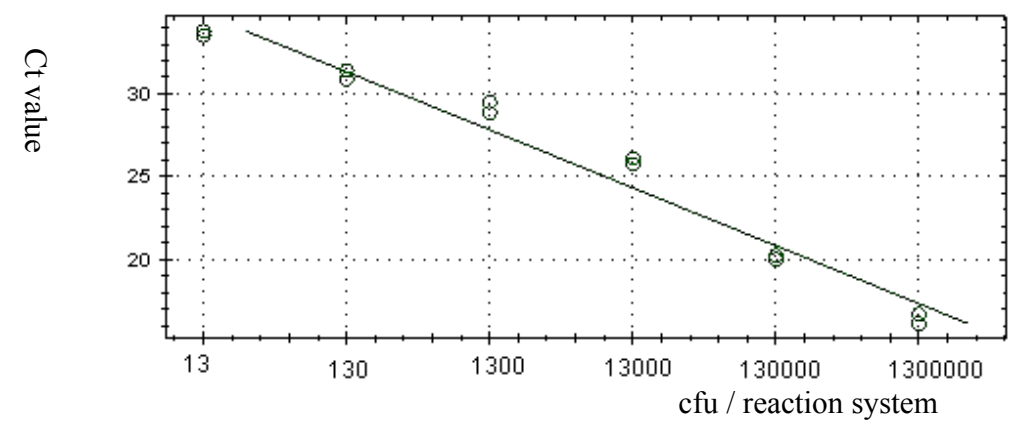

Figure 1. The standard curve established using standard samples with known DNA concentration

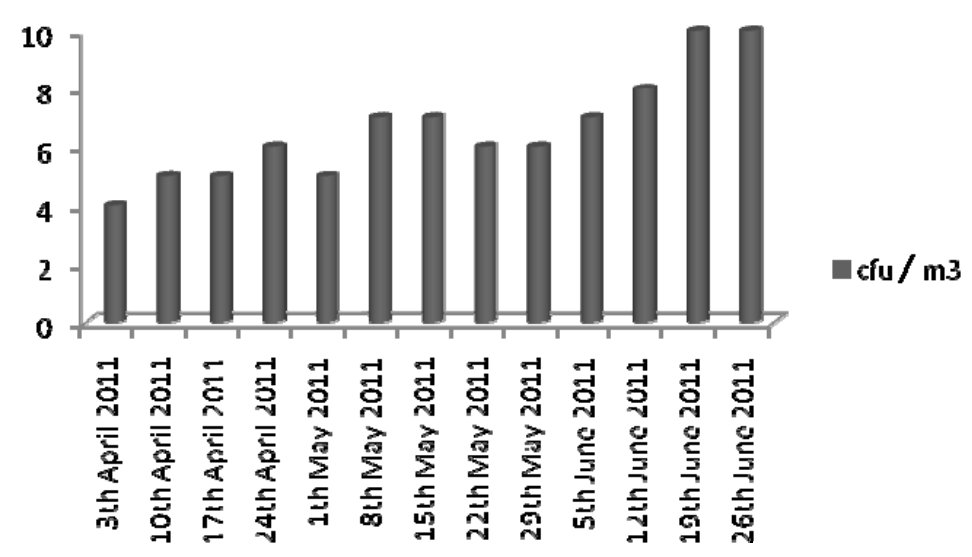

Figure 2. The number of $S$. aureus quantified in samples 